\title{
Internet Adoption in Tourism Industry in China
}

\author{
Hongxiu $\mathrm{Li}^{1}$, and Reima Suomi ${ }^{2}$ \\ 1 Information Systems Institute, Turku School of Economics \\ Turku Center for Computer Science \\ Joukahaisenkatu 3-5 B, 20520 Turku, Finland \\ Hongxiu.li@tse.fi \\ 2 Information Systems Institute, Turku School of Economics \\ Turku Center for Computer Science \\ Rehtorinpellonkatu 3, 20500 Turku, Finland \\ Reima.suomi@tse.fi
}

\begin{abstract}
Information communication technologies (ICTs) have significantly revolutionized the travel industry in the last decade. E-tourism has been developed in travel industry in the world, which helps to realize digitalization of travel service process and value chains in travel industry, and has been used to evaluate the entire range of ICT application in tourism industry. E-tourism has developed variedly in different regions or countries. This research aims to examine how ICTs and Internet have impacted the travel industry in China. This study explores the current e-tourism development in China and examines the use of Internet in travel organizations. In addition, it investigates some issues related to the e-tourism development, including the drivers and barriers in e-commerce adoption from both travel organizations' and travelers' perspectives. The results indicate that in general China is a late-adopter as regards to the adoption of e-commerce in tourism industry. In China only a few innovative travel organizations are at the early adoption stage of Internet and have experienced the benefits and advantages of early-adopters. Though etourism has been a growing trend, travel agency still keeps the main travel service delivery channel in China. This study also suggests that travel organizations in China should learn from developed countries to know how to develop e-tourism and improve the competitiveness of tourism in China.
\end{abstract}

Please use the following format when citing this chapter:

Li, H., Suomi, R., 2008, in IFIP International Federation for Information Processing, Volume 286; Towards Sustainable Society on Ubiquitous Networks, eds. Oya, M., Uda, R., Yasunobu, C., (Boston: Springer), pp. 197-208. 


\section{Introduction}

With the Internet as a commercial medium, new ways of conducting business have developed in almost every sector. Tourism, as an information intensive industry, requires the support offered by information communication technologies (ICTs) and information systems [1-4]. Therefore, ICTs play an increasingly significant role in the global tourism industry development. With the wide application of Internet in business, Internet has been changing the global tourism industry, and e-tourism has being developed in the world. E-tourism helps to realize digitalization of travel service process and value chains in travel industry, which has been used to evaluate the entire range of ICT application in tourism industry, and its development varies in different regions or countries in the world [5].

As tourism industry plays an important role in the Chinese economy, this research aims to examine how ICTs and Internet have impacted the tourism industry in China. This study explores the current e-tourism development in China and examines the adoption of Internet in travel organizations. In addition, it investigates some issues related to e-tourism development, including the drivers and barriers in e-commerce adoption from both travel organizations' and travellers' perspectives. This study suggests that travel organizations in China should learn from developed countries to know how to develop e-tourism and improve the competitiveness of tourism in China.

The paper is organized as follows. It first reviews relevant literature in theories of e-commerce development and e-tourism development in China. It then describes how this study was conducted, together with the research setting. Third, it reports the research findings. Finally, it concludes with a discussion and recommendations for both practitioners and researchers.

\section{Background and Literature Review}

\subsection{E-Commerce Development in China}

To contextualize e-tourism development in China, an examination of e-commerce development in China is required. With the development of Internet penetration in the world, e-commerce has emerged as a global phenomenon. E-commerce is getting popular and increasing its market share in the world [5]. Although e-commerce has experienced its maturity in some economically developed countries, for example the USA, its development in many regions is still in its infancy. As far as the e-commerce development in China is concerned, e-commerce in China is still in its formation stage [6].

In the past several years, with the rapid growth of the population of Internet users in China, e-commerce has expanded rapidly in China. According to the survey conducted by China Internet Network Information Centre (CNNIC), the number of Internet users in China has reached 210 million until the end of 2007, and Internet penetration rate in China has arrived at $16.0 \%$ [7]. In the past several years, the number of Internet users has increased greatly (See Table 1). The number of websites 
in China has arrived at 1.31 million, and most of Chinese websites are operated by enterprises for business [7].

Table 1 The increase of Internet users in China from 2002 to 2007 (M: million)

\begin{tabular}{lllllll}
\hline \multirow{2}{*}{ Time } & Jun. & Dec. & Jun. & Dec. & Jun. & Dec. \\
& 2002 & 2002 & 2003 & 2003 & 2004 & 2004. \\
\hline Internet population(M) & 45.8 & 59.1 & 68 & 79.5 & 87 & 94 \\
Internet penetration rate (\%) & 3.4 & 4.6 & 5.3 & 6.2 & 6.7 & 7.3 \\
\hline \multirow{2}{*}{ Time } & Jun. & Dec. & Jun. & Dec. & Jun. & Dec. \\
& 2005 & 2005 & 2006 & 2006 & 2007 & 2007 \\
\hline Internet population(M) & 103 & 111 & 123 & 137 & 162 & 210 \\
Internet penetration rate (\%) & 7.9 & 8.5 & 9.4 & 10.5 & 12.3 & 16.0 \\
\hline
\end{tabular}

E-commerce in China is multiplying almost as fast as the number of Internet users in China. According to the report from the Research in China (RIC), in 2006 the revenue generated in e-commerce was about $\$ 138.4$ billion in China, and the ecommerce market will continue to expand in China [8]. The e-commerce market in China will be perhaps totally as much as $\$ 654.3$ billion by 2010 [9]. The figures in relation to Internet and e-commerce development in China are optimistic. However, e-commerce development in China is impacted by some barriers, including lack of trust, security risks, lack of credit card and so on [7]. Compared to e-commerce development in developed countries, the adoption of e-commerce in Chinese organizations is also in its infancy. Though there are companies which have achieved success in their e-commerce development, for example, Alibaba and Taobao, most of the Chinese companies have not really employed e-commerce in their business. Currently most of them use the Internet mainly for the purpose of information exchange and information presence, but not integrating with business management and business transactions $[10,11]$.

\subsection{E-Tourism in China}

In the past 20 year tourism industry has developed quickly in China. Since 1999 the Chinese government has taken different strategies to further push tourism development in China, for example establishing three "Golden weeks" holidays. According to the statistics of China National Tourism Administration (CNTA), in China the revenue of tourism industry has arrived at $\$ 1.9$ billion in 2006 , which takes about 4.27 per cent of the total GDP in China [12]. The number of inbound travellers has arrived at about 124.9 million, the number of outbound travellers has arrived at 345.2 million, and the number of domestic travellers has arrived at 1.39 billion [12]. According to the prediction of World Tourism Organization (UNWTO), tourism industry in China will take up to 8.6 percent of world market share and become the world's top tourism industry by 2020 [13].

E-commerce development and the expansion of electronic market in China have attracted travel organizations to employ e-commerce in their business as. Internet has become a new intermediary in travel industry, which brings both challenges and 
opportunities to travel organizations. In fact, travel and tourism industry has been particularly affected by the great advancement and the wide application of ecommerce in business [2-4]. Travel organizations, especially travel service providers, rely heavily on online intermediaries or Internet to offer travel service to their customers. Travel service providers have being shifted from the traditional offline channels (the $\mathrm{i}$ and ii in Figure 1) to the online channels to distribute their travel services to their customers (the iii and iv in Figure 1), which helps them to reduce commitment costs assigned to travel operators or travel agents before and to generate sustainable competitive advantages.

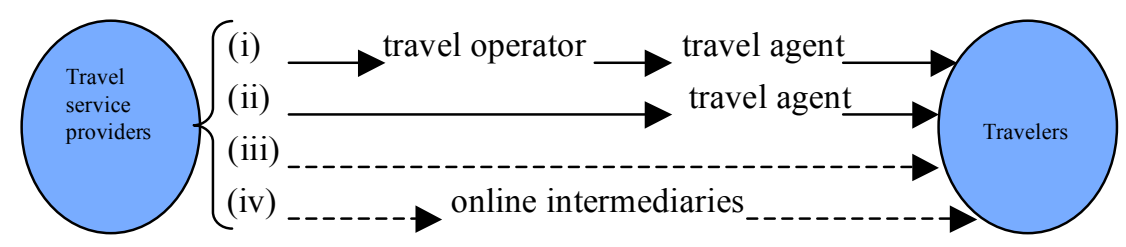

Figure 1 Travel service distribution chain in e-commerce times

In China there are totally about 17957 travel agencies, 12751 hotels, and most of them have already established their websites to offer online travel services. They use the Internet to present travel information, to offer email service, and to offer online booking service to customers. In China, according to the survey conducted by CNNIC in 2007 , only around $3.9 \%$ of Internet users are using the Internet to book travel service, most of the Internet users just use the Internet to look for travel information [7]. In the USA, about $63 \%$ of the Internet users are using Internet to book travel services. Compared to the USA, in China the demand market of online travel service booking is still very small [7]. E-tourism in China is still at its initial stage, which is in line with the e-commerce development in China [14]. The traditional offline travel service keeps competitive in the travel market in China since a large amount of Chinese travellers still rely more on the traditional intermediary - travel agencies to book travel service. The online channels seem not so attractive to Chinese travellers, and even online intermediaries need to cooperate with travel agents to offer travel services to travellers $[15,16]$. Compared to the e-tourism development in developed countries, the online channels illustrated in Figure 1 seem not so important for travel organizations in China. It is evident that e-tourism in China is lagging behind the developed countries.

\section{Method}

This study aims to explore the issue on e-tourism development in China. In order to fulfil the objectives of this study, different methods were used. In this study both qualitative and quantitative methods were adopted. As Cresswell (2003) explained that qualitative and quantitative methods are complementary rather than competing 
for research [17]. The study issue is investigated based on the data collected in different travel organizations in China.

First a qualitative approach was adopted in order to achieve an appreciation of the research topic and to develop a set of appreciate variables in the survey and a set of questions for the interviews. Some travel organizations in China have been chosen in the study and their websites have been visited. An examination on the websites was undertaken based on the following aspects: website presence, e-mails service, online information services, online booking and offline booking. A review based on the data collected in this phrase helps the researchers to achieve a general understanding about the level of e-commerce in tourism industry in China.

Then interviews were conducted in some travel service providers and travel agencies, which aimed to explore the drivers and barriers in e-commerce adoption from travel organizations' perspectives and the current e-commerce adoption in tourism in China. The interviewee sampling were targeted at the owners, managers or sales managers of travel organizations in China which had began to employ Internet in their business. Structured interviews were conducted in this research. The interviewed questions were first developed for the interviews in advance which mainly focus on the e-commerce application in travel organizations, including the background of organizations, e-commerce application in business, the perceived benefits and barriers in their e-commerce application in business, the future plan for e-commerce development in business and their perception of e-tourism development in tourism industry. And all the interviewees were asked to answer the same questions. Before interviews, all the interviewees were informed of the interviewed topic and interviewed questions in advance in order to make sure that they know about ecommerce application in their organization and can offer some valuable data for this research. The interviewees were also asked to express their perceptions of ecommerce development in tourism in China. Every interview lasted around 1 hour.

In this study totally 20 face-to-face interviews were conducted in 6 travel service providers and 12 travel agencies. 3 of the 6 travel service providers are the main airlines in China, 1 is an international airline company in Europe which has offices in China, and the other 2 are four-star hotels in China. Among the travel agencies, 10 of them are traditional travel agencies located in big cities in China, including Beijing, Shanghai, Guangzhou, Wuhan and Shanghai, and the other 2 are the biggest and most successful online travel intermediaries in China - Ctrip and Elong companies. The details are illustrated in Table 2.

Table 2 Formal interviews

\begin{tabular}{lcc}
\hline Company & Number of companies & Number of interviews \\
\hline Airlines & 4 & 6 \\
Hotels & 2 & 2 \\
Travel agencies & 10 & 10 \\
Online travel intermediaries & 2 & 2 \\
\hline
\end{tabular}

The interviewees are mainly the sales managers, e-commerce department managers or directors, general managers, or deputy general managers. Their rich 
experience in tourism industry offers valuable data for our research. Content analysis was employed in the study to analyze the interview data.

Finally a quantitative survey was conducted in the study in order to investigate etourism condition in China from travellers' perspective - the demand market. It aims to examine the traveller's perception of e-tourism in China. The questionnaire includes some questions based on background studies and secondary research. In the survey a questionnaire was developed to collect empirical data. The respondents were some onboard travellers of one interviewed airline company. The respondents were asked to report on the barriers and benefits of online travel service booking, their travel information searching channels, and travel service booking channels. A 5-point scale was used in the survey to investigate the research topics.

The survey was conducted by the airline company onboard. In the study totally 190 copies were received, and 169 copies are usable. The data of the questionnaire were put into SPSS and descriptive statistics method was employed in the data analysis.

\section{Research Findings}

Based on the collected data, it is indicated that the general state of e-tourism in China is still in its early stage. Most of the interviewees agreed that though e-tourism ranks highly in e-commerce adoption in the world, and it has achieved success in some developed countries, in China currently e-tourism has been developed quite slowly in travel industry. In their opinion, e-tourism is a good option for them to further develop their business in the world and widen their market, and they would like to develop e-tourism. In fact, some of the interviewed travel organizations have already adopted e-commerce in their business and regarded e-commerce as their important strategies in their business because of the advantages of e-commerce. However, the role of e-commerce seems not to be as important as they expected because of some barriers. According to their opinion, currently e-commerce is not their main business focus and there is still a long way for them to develop e-commerce in tourism industry in China.

\subsection{E-Commerce Development in Travel Organizations in China}

In China travel organizations have tried to use e-commerce in their business for the advantages of e-commerce. According to the comments from the interviewees, most of them agreed that e-commerce can offer direct communication and access to their customers, reduce their dependence on intermediaries, work more efficiently, reduce cost and widen their market to the world. All of the interviewees have mentioned that fear of lagging behind their competitors is also an important driver for them to adopt e-commerce in their business, especially for the big travel organizations. But for SMEs in travel industries, it is not a driver. In fact the competition between big travel organizations is more furious than in SMEs in travel industry in China, and normally big travel organizations pay more attention to innovations than SMEs. 
The interviewees discussed their e-commerce adoption from the following aspects: website establishment and presence, online travel service booking, online travel service distribution and value chain, online cooperation and business network establishment.

All the interviewed companies have established their own websites and have used their websites to perform marketing and promotion. In their opinion, most of the travel organizations in China, including the SMEs in travel industry, have already established their own websites, since the Internet population size is keeping increasing every year and has taken about one eighth of the population size in China. Most of the interviewees agreed that their website service is poor. The main deficiencies are illustrated in following aspects: poor travel information, no updated travel information, lack of efficient navigation, no good online booking service and no English version. Only 3 of the interviewees stated that their website service is good, including the two online travel intermediaries. The interviewees have discussed about the reasons why their website service is poor. All of them agreed that lack of technological knowledge and professionals in ICT field is the main reason. Most of them have outsourced their website establishment and maintenance service. It seems that most of them are going to employ professional ICT talents to work for them and improve their website service in the future.

Online travel service booking, online travel service distribution and value chain of travel organizations are close related to each other. There are different answers from the interviewees on this point. According to the discussion of the interviewees from the airlines and hotels, they agreed that reducing their dependence on the intermediaries is one of the main drivers for them to develop e-commerce in their business. They can offer online travel service booking directly to their customers without the cooperation with travel operators or travel agencies. But in fact they still rely on travel agencies quite a lot since the share of online booking is still very low in their whole market. Call to or visiting travel agencies or airlines offices is still popular in travel services booking in China. Even the two interviewees from the online travel intermediaries stated that they have to rely on travel agencies or agent heavily. Though some Chinese travellers book their tickets online, they can not complete the whole transaction process online. They can send emails or SMS to their customers to inform them of their booking information, and then they need to rely on their cooperated partners in different locations in China to delivery the e-tickets or paper tickets to their customers and receive the payment for the tickets. The interviewees from both the airlines and the online intermediaries agreed that lack of trust and security risks are the main obstacles, and reimbursement regulations in China can be a barrier as well. In China, only the receipt of the e-tickets or paper tickets can be used for reimbursement, which enforces travellers to get the receipt for reimbursement by the traditional distribution channel even though e-ticket can offer convenience to them. The interviewees from the travel agencies agreed with them on this point. For travel agencies their online booking service has not been developed as well as in travel service providers. Though they offer online booking service, but they rely more on offline channel for travel service distribution because traveller would like to book travel service more on the offline channels. Therefore, the distribution chain and value chain in tourism industry in e-commerce time in China has emerged as illustrated in Figure 2. In China travel agent still plays an important role in travel 
service distribution and the traditional offline booking channels ( $\mathrm{i}$ and ii in Figure 2) are still more important than the online booking channels (iii and iv in Figure 2).

Though online channel offers more opportunities for the travel service providers and online intermediaries, they still need the cooperation with travel agents in their online booking services. Compared to the general travel service distribution chain we discussed in e-commerce time in developed countries, in China e-commerce in tourism industry is still at the early stage since online booking has not been widely adopted in travel organizations.

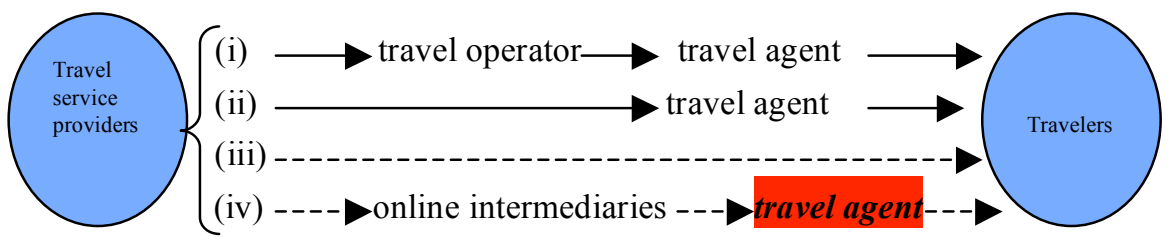

Figure 2 Travel service distribution chain in China

Buhalis and Deimezi (2004) argued that cooperation and competition among travel organizations is a feature of the emerging online tourism industry [5]. Internetbased cooperation among travel organizations impels each other to establish their business networks, which can help them to integrate the newly created resources in their business networks and existing resources to develop new products or services to their new customers [18]. In travel industry, business networks can be established among clusters of firms to establish value chain among them, including hotels, sightseeing companies and transportation companies based on their access to each other's resources $[19,20]$. The interviewees did not discuss this point so much. They agreed that they do not use Internet to cooperate with their partners so much though Internet can make their work in cooperation much efficient. Normally they just use emails to transfer information between each other. They still rely more on the traditional cooperation channels, for example face-to-face meeting and call to each other. It is consistent with the e-commerce development in travel industry in China. In the early stage of e-commerce adoption, it is hard for travel organizations to realize Internet-based business cooperation and establish their business networks. In their opinion, it is what they expected in the future when e-commerce has achieved maturity in travel industry in China.

\subsection{E-Tourism Adoption from the Demand Side in China}

The customers are investigated on their perception of online travel service booking. Among the 169 respondents, $97.2 \%$ of them are Internet-users, and 99 of them $(58.8 \%)$ have online travel service booking experience.

According to the results of quantitative data, security risks and lack of trust are regarded as the most important barriers in online travel service booking, and the shortcomings in the service offered on the Internet by travel organizations is also an important barrier, which is concluded based on the mean comparison (See Table 3). 
The results are in consistent with the results from the qualitative interview data. As regards the benefits of online booking, by mean comparison, convenience, saving time and low prices are the main three benefits (See Table 3 ).

Table 3 Traveler's perception on barriers and benefits of e-tourism in China

\begin{tabular}{|c|c|c|c|c|c|}
\hline Barriers & Mean & SD & Benefits & Mean & $\mathrm{SD}$ \\
\hline Security risks & 1.61 & 1.098 & Convenience & 1,70 & 1,386 \\
\hline Lack of trust & 1.94 & 1.347 & Saving time & 2,18 & 1,197 \\
\hline $\begin{array}{l}\text { Shortcomings in the service } \\
\text { offered on the Internet }\end{array}$ & 3.18 & 1.954 & Low prices & 2,92 & 1,792 \\
\hline Lack of customized service & 3.45 & 1.688 & $\begin{array}{l}\text { Service around the clock } \\
\text { available }\end{array}$ & 3,22 & 2,070 \\
\hline Lack of credit card & 3.77 & 2.267 & $\begin{array}{l}\text { Good possibility to compare } \\
\text { between different offerings }\end{array}$ & 4,11 & 1,605 \\
\hline Long delivery time & 3.79 & 1.459 & $\begin{array}{l}\text { Availability of personalized } \\
\text { products and services }\end{array}$ & 5,10 & 1,546 \\
\hline Lack of Internet access & 5.23 & 2.458 & Avoidance of personal service & 5,74 & 1,446 \\
\hline
\end{tabular}

As regards travel information searching and travel service booking channels. Travel agency is ranked as the most important travel information searching channel and the Internet is not so important, which is based on mean comparison (See Table 4).

Table 4 Travel information search and service booking channels

\begin{tabular}{lcc}
\hline & Mean & Std. Deviation \\
\hline Travel agency & 1.99 & 1.322 \\
Friends & 2.04 & 1.145 \\
Experience, habit & 2.29 & 1.486 \\
Internet & 2.31 & 1.316 \\
Advertisement & 3.24 & 1.522 \\
\hline
\end{tabular}

The result is also in consistent with the results from travel organizations side. For travel service booking, travel agency is more important than Internet, $45.6 \%$ of the respondents would like to use travel agency to book travel service, and $33.1 \%$ of them would like to use online booking. The results are higher than the results reported by China Internet Network Information Centre [5], and higher than the interview results.

\section{Discussion}

It is evident that ICTs play an important role in the operation and management of tourism industry since tourism is information intensive industry, and has been quite 
fit with the new interactive media - Internet. In fact in many developed countries etourism has achieved success. It has become the main travel service distribution channel and the main marketing mechanism in the worldwide market and has constituted one of the largest and fastest growing segments of e-commerce. Travel organizations adopt e-commerce in their business for different drivers, for example for communication, reducing intermediaries and improving working efficiency and processes. In China travel organizations still rely on some suitable technological tools in their business, and they are in the infancy period of e-commerce/Internet adoption. In general Chinese travel organizations are the late-adopters of innovation as regards to the adoption of e-commerce in tourism industry in China.

The study demonstrates that in China Internet has been adopted widely and etourism has been developed in travel organizations. It seems that some travel organizations are willing to adopt the modern Internet technology in their business and some are reluctant to use it though e-tourism is a future trend in the world with the wide penetration of Internet into people's life. The business advantages of etourism have not been experienced by most travel organizations in China. In China only a few innovative travel organizations are at the early adoption stage of Internet and have experienced the benefits and advantages of early-adopters with the face of some barriers and difficulties in innovation adoption. The majority of travel organizations in China are belonging to the late majority or laggard adoption stage. In general Chinese travel organizations are the late adopters of e-commerce. Currently tourism industry in China is facing fierce competition, to learn from the developed countries in their e-tourism development might be helpful for Chinese travel organizations to really understand the benefits and advantages of e-tourism and adopt Internet in their business, which can help Chinese travel organizations to enhance competitiveness and address the challenges in the e-commerce times. In addition, in order to expand e-market in tourism industry in China, travel organizations should take some strategies to stimulate customers' adoption of ecommerce, for example offering cheaper price to customers if customers adopt online booking. Travel organizations should also take strategies to integrate their business with the Internet to realize more efficient and less cost business cooperation with business partners in their value chain.

The results in this study reveal that though e-tourism has been a growing trend, but travel agency still keeps the main travel service delivery channel in China on the perspective of both travel organizations' and traveller's perspectives. Barriers existed in the e-tourism development can explained this phenomenon in China, which are also $s$ the factors which impact the adoption rate of e-commerce in tourism industry in China.

In summary, the results in this study support the following conclusions. First, in general China is a late-adopter of innovation as regards to the adoption of ecommerce in tourism industry. Second, In China only a few innovative travel organizations are at the early adoption stage of Internet adoption and have experienced the benefits and advantages of early-adopters. Third, e-tourism has been a growing trend, but travel agency still keeps the main travel service delivery channel in China. 


\section{Limitations and Future Research}

This study has offered some valuable insight into studies on e-tourism development in China. A number of limitations of the study need to be acknowledged when we interpret the results. First, the empirical study was conducted only in China. Second, only big travel organizations were chosen as the targets in our empirical study. More travel organizations, including both big companies and SMEs in travel industry will better support the assumptions in the study. In the future further studies on how to develop e-tourism in developing regions need to be conducted to support the Internet and e-commerce diffusion in travel industry.

\section{Reference}

1. V. Cho, World Wide Web Resources, Annals of Tourism Research 25(2), 518521(1998).

2. D. Buhalis, Tourism and Information Technologies: Past, Present and Future, Tourism Recreation Research 25(1), 41-58(2000).

3. R. Law, Internet in Travel and Tourism-Part I, Journal of Travel \& Tourism Marketing 9(4), 83-87(2000).

4. R. Law, et al. The Impact of the Internet on Travel Agencies, International Journal of Contemporary Hospitality Management, 16(2), 100-107(2004).

5. E. M. Rogers, New Product Adoption and Diffusion, Journal of Consumer Research 2(1976), 290-301(1976).

6. H. X. Li, and R. Suomi, E-commerce Development in China: Opportunities or Challenges? In Proceedings of the IADIS International Conference on Ecommerce (Krishnamurthy, S. \& Isaias, P. Ed.), pp. 413-417, IADIS Press, Barcelona, Spain, 2006.

7. China Internet Network Information Center (CNNIC), The 21th Statistical Report on Internet Development in China, http://www.cnnic.net.cn/uploadfiles/pdf/2007/7/18/113918.pdf

8. Research in China (RIC), The Benefit Model in E-commerce in China in 2006, http://www.pday.com.cn/research/2005/572_ecommerceway.htm

9. China Market Information Centre (CCID), B2B Market Will Continue Develop in China, http://news.ccidnet.com/art/1032/20060214/428239_1.html.

10. Z. X. Tan, and W. Ouyang, Diffusion and Impacts of the Internet and Ecommerce in China, Electronic Markets 14(1), 25-35(2004). 
11. X. H. Guo, and G. Q. Chen, Internet Diffusion in Chinese Companies, Communications of ACM 48(4), 54-58(2005).

12. China National Tourism Administration (CNTA), The Annual Statistical Report of Tourism Industry in China in 2006, http://www.cnta.gov.cn/news_detail/newsshow.asp?id=A20071023943253500589

13. China National Tourism Administration (CNTA), Outbound Travel Development in China,

http://www.cnta.gov.cn/news_detail/newsshow.asp?id=A20075101738546353446

14. L. Li, and D. Buhalis, E-commerce in China: The Case of Travel, International Journal of Information Management 26(2006),153-166(2006).

15. J. Lu, and Z. Lu, Development, Distribution and Evaluation of Online Tourism Services in China, Electronic Commerce Research 4(2004), 221-239(2004).

16 Y. B. Lu, et al. Tourism and Travel Electronic Commerce in China, Electronic Market 17(2), 101-112(2007).

17. J. W. Cresswell, Research Design: Qualitative, Quantitative and Mixed Research Methods and Approaches, Second edition, Sage Publications, London, 2003.

18. M. Hitt, et al. Strategic Entrepreneurship: Entrepreneurial Strategies for Wealth Creation, Strategic Management Journal 22(6/7), 479-491(2001).

19. R. Gulati, et al. Strategic Networks, Strategic Management Journal 21(1), 203215(2000).

20. A. Wong, et al. Developing Relationship in Strategic Alliances: Commitment to Quality and Cooperative Interdependence, Industrial Marketing Management 34(2005), 722-731(2005). 